\title{
Geophysical Monitoring of Ground Surface Deformation Associated with a Confined Aquifer Storage and Recovery Operation
}

\author{
Alain Bonneville ${ }^{1}$ (D) Essam Heggy ${ }^{2}$. \\ Christopher Strickland $^{1} \cdot$ Jonathan Normand ${ }^{2}$. \\ Jeffrey Dermond ${ }^{1} \cdot$ Yilin Fang $^{1} \cdot$ Charlotte Sullivan $^{1}$
}

Received: 11 February 2015 / Accepted: 28 July 2015 /

Published online: 11 August 2015

C The Author(s) 2015. This article is published with open access at Springerlink.com

\begin{abstract}
One important issue in the storage of large volumes of fluids, mainly water and $\mathrm{CO}_{2}$, in the deep subsurface is to determine the resulting field-scale-induced displacements and consequences of overpressures on the mechanical integrity of the storage reservoir and surroundings. A quantifiable estimation of displacement can be made by combining the robust, cost-effective, and repeatable geophysical techniques of micro-gravimetry, differential global positioning system (DGPS), and differential synthetic aperture radar interferometry (DInSAR). These techniques were field tested and evaluated for the first time on an active large-volume aquifer storage and recovery (ASR) project in Pendleton, Oregon, USA, where three ASR wells are injecting up to 1.9 million $\mathrm{m}^{3}$ year $^{-1}$ into basalt aquifers to a depth of about $150 \mathrm{~m}$. Injection and recovery of water at the wells are accompanied by significant gravity anomalies and vertical deformation of the ground surface localized to the immediate surroundings of the injection wells as evidenced by DGPS and gravity measurements collected in 2011. At a larger scale, and between 2011 and 2013, DInSAR monitoring of the Pendleton area shows subcentimetric deformation in the western part of the city and close to the injection locations associated with ASR cycle. Deformations are found to be temporally out phased with the injection and recovery events due to complex groundwater flow. A numerical simulation of the effect of the water injection gives results in good agreement with the observations and confirms the validity of the approach, which could be deployed in similar geological contexts to look at the mechanical effects of water and gas injections.
\end{abstract}

Keywords Water storage $\cdot \mathrm{CO}_{2}$ storage $\cdot$ Ground deformation · INSAR · GPS · Gravity · ASR . Aquifer storage and recovery

Alain Bonneville

alain.bonneville@pnnl.gov

1 Pacific Northwest National Laboratory, MSIN K6-84, P.O. Box 999, Richland, WA 99352, USA

2 Jet Propulsion Laboratory, Caltech, Pasadena, CA, USA 


\section{Introduction}

The injection of large volumes of fluids, mainly water and $\mathrm{CO}_{2}$, in subsurface reservoirs is increasingly performed in various applications (e.g., aquifer storage and recovery, enhanced oil recovery, carbon sequestration) raising several concerns about the mechanical integrity of the reservoirs themselves and their surroundings. Determining the field-scale-induced displacement of fluids and the temporal and spatial deformations of the ground surface is thus a priority. Both of these issues can be addressed by combining the reliable, large-scale and costeffective geophysical techniques of microgravimetry, differential global positioning system (DGPS) and differential synthetic aperture radar interferometry (DInSAR).

The determination of the time-dependent density distribution of materials in the subsurface potentially fulfills the above requirements for monitoring techniques to measure field-scale displacements of reservoir fluids induced by injection of liquid or gas. Moreover, accurate measurements of temporal ground deformations reflect the geomechanical responses and their spatial changes. Using micro-gravimeters and a DGPS, very small gravity anomalies and surface deformations can be mapped and tracked through time. Surface displacements of the ground can also be measured accurately using DInSAR. Each of these methods has been implemented on active storage fields (water, natural gas, or $\mathrm{CO}_{2}$ ) and recently the DInSAR technique was successfully used at a commercial $\mathrm{CO}_{2}$ sequestration site at In Salah, Algeria, where a surface uplift of $5 \mathrm{~mm}$ year ${ }^{-1}$ has been observed after injection of $\mathrm{CO}_{2}$ (Vasco et al. 2010; Morris et al. 2011). The Algerian desert represents one of the most favorable environments in which to perform such displacement measurements because the unvegetated-exposed surface maximizes radar waves phase coherence for DInSAR analysis. Assessing such deformation in vegetated terrains is challenging due to the occurrence of complex backscattering that causes the degradation of radar wave phase coherence.

Four-dimensional (4D or time-lapse) microgravimetry - the temporal change of gravity at the microGal scale $\left(1 \mu \mathrm{Gal}=10^{-6} \mathrm{~m} / \mathrm{s}^{2}\right)$ - is a cost-effective and relatively rapid means of observing changes in density distribution in the subsurface, particularly those caused by the migration of fluids. Time-lapse gravity has been used since 1961 (Allis and Hunt 1986), but substantial improvements in gravimeter technology, and the advent of highly precise GPSs, have led to rapid growth in microgravity applications in the last 10 years. This technology has been successfully applied in geothermal fields, volcano monitoring, petroleum production, and reservoir characterization (Biegert et al. 2008), as well as near-surface groundwater infiltration and migration through sedimentary units (Chapman et al. 2008; Leirião et al. 2009).

Deformation of the ground surface due to anthropogenic processes (oil and gas production, mining, groundwater extraction) has been studied by numerous researchers over the past several decades (Poland 1984; Gambolati et al. 2006; Galloway and Burbey 2011). Withdrawal of groundwater causes subsurface stress changes that can mechanically deform geologic media and produce measureable deformations and even ground failures at the surface (Galloway and Burbey 2011). Introduction and extraction of subsurface fluids can cause threedimensional (3D) deformation (Burbey 2001; Burbey et al. 2006; Gambolati et al. 2006; Bell et al. 2008), and measuring both horizontal and vertical displacements can provide important information for understanding the effects of the injection of fluids in the subsurface.

In this study, the performances of these techniques are quantified for the first time on an active large-volume aquifer storage and recovery (ASR) project where sufficient geological data and a documented time series of injection exist. ASR projects, in which very large volumes of water (up to 1.9 million $\mathrm{m}^{3}$ year $^{-1}$ ) are injected and removed annually, are 
particularly relevant for testing field-scale gravity and surface deformation. For many sites, it is possible to recover almost all of the injected water volume. The injection is accomplished by one or more dual-purpose wells (both injection and extraction). Injection volumes, pressures, and water elevations are monitored and recorded; tracers are sometimes added. Many of the deeper aquifer sites have new wells with suites of geophysical wireline logs. More than 300 ASR sites are in operation in the USA; the largest well fields store about 9.5 million $\mathrm{m}^{3}$ of water. Because $1 \mathrm{~m}^{3}$ of water equals one metric ton, and supercritical $\mathrm{CO}_{2}\left(\mathrm{scCO}_{2}\right)$ has an average density of about $600 \mathrm{~kg} / \mathrm{m}^{3}$, sites that inject more than 1 million $\mathrm{m}^{3}$ years ${ }^{-1}$ might produce carbon storage scale deformation and thus can be used as proxy of the future $\mathrm{CO}_{2}$ storage projects that should come in line in the next decade. Of these 300 ASR sites, most are in unconfined aquifers or are at very shallow depths. To be amenable to calibration of geomechanical properties and gravity and deformation response, very large-volume projects in confined bedrock aquifers in areas of low population or at the margins of heavily populated areas are needed. The basalt aquifer ASR project in Pendleton, Oregon, USA, meets the needed conditions. Results and interpretation of gravity and DGPS surveys are presented concurrent with 20 Radarsat-2 DInSAR scenes collected between July 2011 and March 2013 over the Pendleton area.

\section{The Pendleton ASR Project and Geological Context}

The City of Pendleton $\left(45.7^{\circ} \mathrm{N}, 118.8^{\circ} \mathrm{W}\right)$ is in the Umatilla River valley of northeast Oregon, USA. Its underlying geology is quite simple; a large accumulation of Miocene basalt lava flows, known as the Columbia River flood basalts (CRBs), covers most of the region. Three main units can be distinguished: the Grande Ronde, the Wanapum, and the Saddle Mountains basalts formations (Fig. 1). More than 300 individual lava flows of variable extent have been identified to have a maximum composite thickness of $5 \mathrm{~km}$ within the central portion of the Columbia Basin (Reidel et al. 1989; Reidel et al. 2002). Fractured and vesiculated basalt flow tops and interflow zones serve as aquifers and avenues for water transport (Fig. 1).

Since 2003, the Oregon Water Resources Department and the City of Pendleton have installed three ASR wells into discontinuous basalt aquifers to a maximum depth of about 331 m: Byers well, Stillman well, and well 14 (Fig. 1). The Stillman well has experienced some problems related to the presence of air in the well during injection and was not used for water recovery, but the two other wells have operated smoothly since project initiation. Up to 1.9 million $\mathrm{m}^{3}$ years ${ }^{-1}$ of treated surface water are injected from January through June in the permeable interflow zones located between depths 60 and $150 \mathrm{~m}$. The project then recovers, or produces, about 1.7 million $\mathrm{m}^{3}$ years ${ }^{-1}$ from June through November. Actual recovery dates vary from year to year, depending on precipitation and demand. Since the beginning of the ASR project in 2004, the average annual decline of static groundwater levels has dwindled to $0.46 \mathrm{~m}$, less than half of what it was, $1.04 \mathrm{~m}$, prior to initiation of the project (City of Pendleton 2009).

Because of the sensitive nature of storing such quantities of potable water, the Pendleton ASR is closely monitored for chemical and biological contaminants. In contrast, the localized physical changes associated with the injection/extraction cycle of the ASR have not been monitored, so there are currently no data to indicate whether associated geomechanical changes have occurred. 


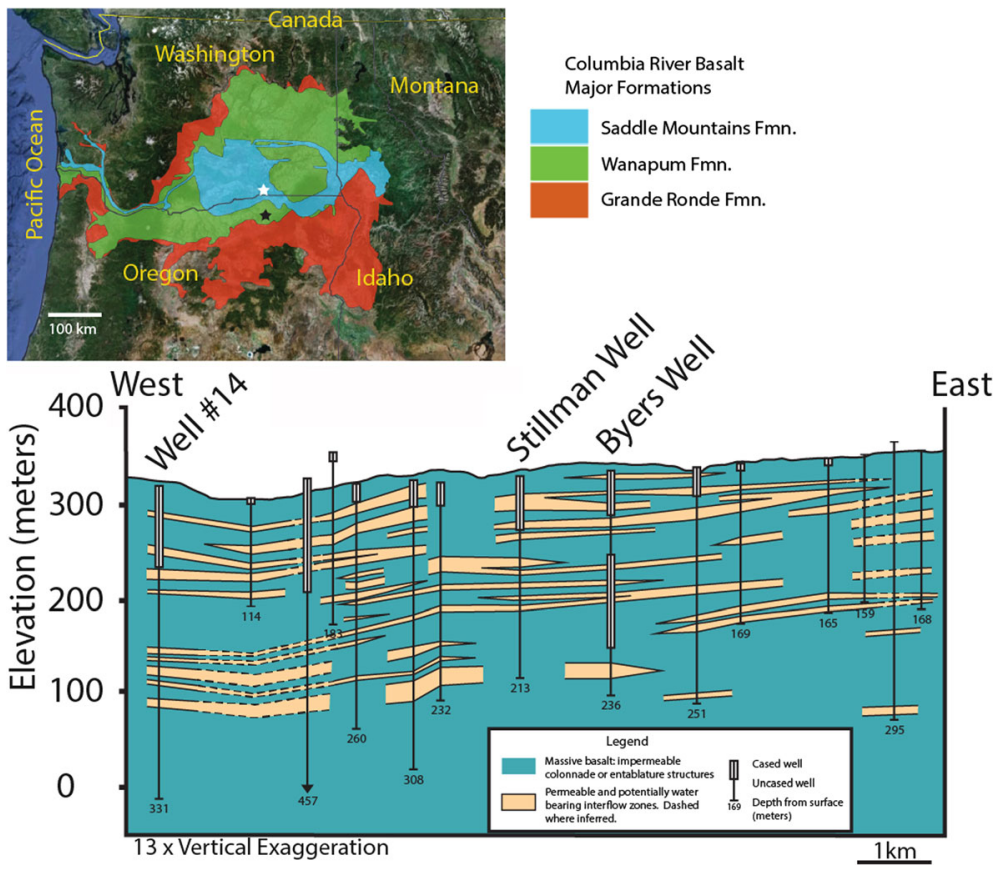

Fig. 1 A 11-km-long schematic cross section through the discontinuous basalt reservoirs system underlying Pendleton (after CH2M-HILL 2002). Beige bodies represent potential water-producing interflow zones interbedded in the massive basalt. Vertical black lines represent wells and the rectangular boxes the cased portion of the wells. In the upper inset, the Miocene Columbia River continental flood basalts (after Reidel et al. 2002) are represented. The City of Pendleton is indicated by a black star and the nearby Wallula $\mathrm{CO}_{2}$ storage pilot site in basalt (McGrail et al. 2011) is indicated by a white star

\section{Methodology and Processing}

\subsection{Differential GPS}

In an effort to approach centimeter-scale accuracy in the leveling GPS survey, differential measurements must be used. This is accomplished using two or more GPS signals obtained at different locations. Because a GPS signal involves several sources of error, including satellite ephemeris errors, clock errors, and atmospheric distortion effects, a Real-Time Kinematic (RTK) technique was used for the geodetic work (US Army Corps of Engineers 2007).

The GPS and gravity stations were implemented along four profiles centered on two active injection wells (Fig. 2): stations 3-13 near Byers well, and stations 2 and 17-30 close to well 14. Semi-permanent markers were installed, allowing for better control of data points. GPS surveys were conducted following guidelines described by Henning (2010). Three GPS measurements were collected at each station using a 30-s occupation time for each measurement. Under these conditions GPS accuracy is expected to be better than $2 \mathrm{~cm}$.

GPS measurements were acquired on 5 days in 2011: May 27, June 11, June 23, July 25, and September 13. Elevation changes (or deformations) were calculated as simply the difference between the elevation measured at a specific date and the one measured at another date. 


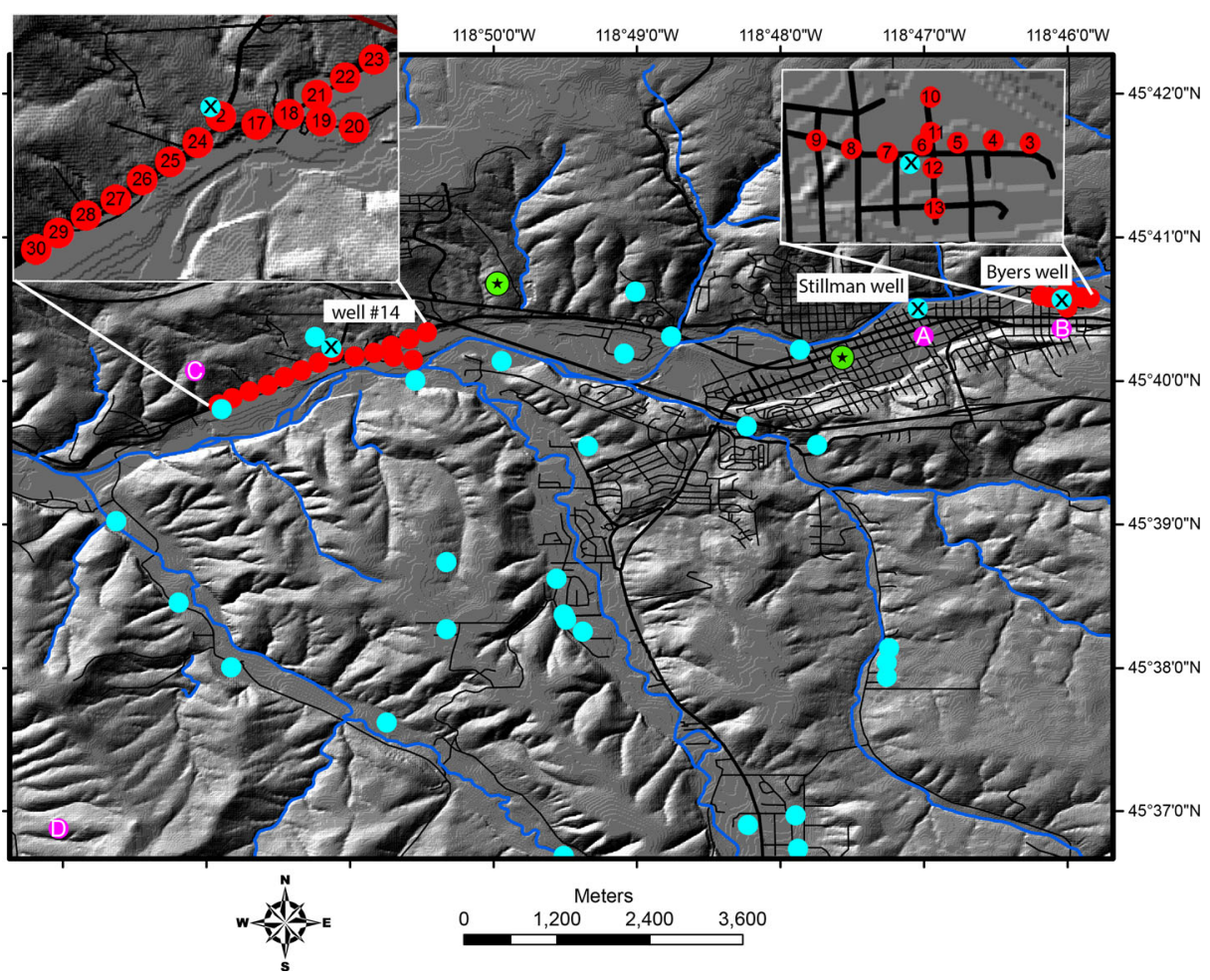

Fig. 2 Location of DGPS and gravity stations (red dots) and water wells (blue dots). The Byers and Stillman wells are located in the city itself and well 14 is on the western edge of the city. Stars indicate existing National Geodetic Survey locations used as references stations (bases) for the DGPS surveys. Lettered pink dots (A-D) correspond to areas where DINSAR time series where determined

\subsection{Gravity}

Gravity data collected at the GPS stations (Fig. 2) were tied to the National Oceanic and Atmospheric Administration/ National Geodetic Survey gravity benchmark, Pendleton, located about $24 \mathrm{~km}$ southwest of Pendleton on Emigrant Hill in the Blue Mountain foothills. Measurements were made with a LaCoste and Romberg Model D gravimeter, in an overlapping loop pattern modeled after that of Roman (1946), whereby each station is occupied three times with a minimum of three independent readings at each occupation.

Three gravity surveys were conducted on June 5, July 25, and September 25, 2011. The surveys corresponded respectively to near peak storage, after 3 weeks of extraction, and near complete extraction. Each survey was conducted during a single day and began and ended with an occupation of a far-field base station, forming a daily loop.

\subsection{DInSAR}

For the Pendleton site we used 22 Radarsat-2 scenes acquired in the ultra-fine resolution mode (U70) in the ascending direction. The scenes were obtained from the cooperative program of the Canadian Space Agency and the German Aerospace Center. Only 20 Radarsat-2 scenes 
were selected to perform the line-of-sight (LOS) displacement study as they satisfy the perpendicular baseline condition to be less than $200 \mathrm{~m}$ for each pair of scenes. The period considered for this LOS displacement study corresponds to acquisitions starting July, 2011 and ending in March, 2013. Data from the Radarsat-2 scenes partially overlap with GPS and gravity data and were used to compare results obtained with those methods. DInSAR is widely used to study large-scale deformations such as earthquakes [e.g., Madsen and Zebker (1998); Fialko et al. (2001)].

For two or more SAR complex scenes, the DInSAR technique is used to measure surface displacement maps between two or more scene acquisitions. These maps represent the path variation of the emitted radar signal between the satellite and the ground (Gabriel et al. 1989).

The Small Baseline Subset (SBAS) algorithm by Berardino et al. (2002) is used to correct for phase distortion from atmospheric water vapor and the ionospheric effects in the backscattered radar signal. The SBAS algorithm, based on a minimum-norm criterion of the velocity deformation, which is estimated with the singular value decomposition method (Stewart 1993), estimates the atmospheric and ionospheric noise, and inverts the interferograms to generate time series with a LOS standard deviation of less than $1 \mathrm{~mm} / \mathrm{year}$ on average. The LOS data products of the inversion are discussed in Section 4. More details about DInSAR processing can be found in Gabriel et al. (1989), Rosen et al. (2000) and Hanssen (2001).

\section{Data}

\subsection{DGPS Data (Fig. 3)}

Substantial DGPS-measured elevation changes outside the measurement errors were observed during 2011. Errors in the measured elevation for individual stations varied between 0.1 and $1.6 \mathrm{~cm}$. The largest errors occurred at stations 8 and 10 near Byers well where dense vegetation and infrastructure interfered with radio communication. Rapid elevation changes occurred across the entire survey area between June 11 and June 23, 2011. Elevation changes at individual stations are measured relative to the base station and an additional source of error is due to movement of the base reference. One way to address this error is to measure a farfield location established $3 \mathrm{~km} \mathrm{NW}$ of the westernmost base station. Elevation errors at this station for a given acquisition date were 0.2 to $2.1 \mathrm{~cm}$ and observed elevation changes during the entire study were -2.0 to $2.2 \mathrm{~cm}$. An upper bound of $\pm 2.2 \mathrm{~cm}$ error in the base station elevation change should thus be considered in analyzing the effects of this error on the DGPS changes at the other stations. Water injection from the ASR project occurs at spatially separated injection locations and it is instructive to show deformations not only at the larger scale but for the locations surrounding each of the injection wells.

\subsubsection{Near-Well Deformations}

Most of the largest elevation changes occurred during injection, between May 27 and June 23, 2011. For stations surrounding a given well and for time periods close to the beginning or end of water injection it may be reasonable to expect a correlation between radial distance and elevation change and various trends can be observed. Near Byers well, the observed elevation 
(a)

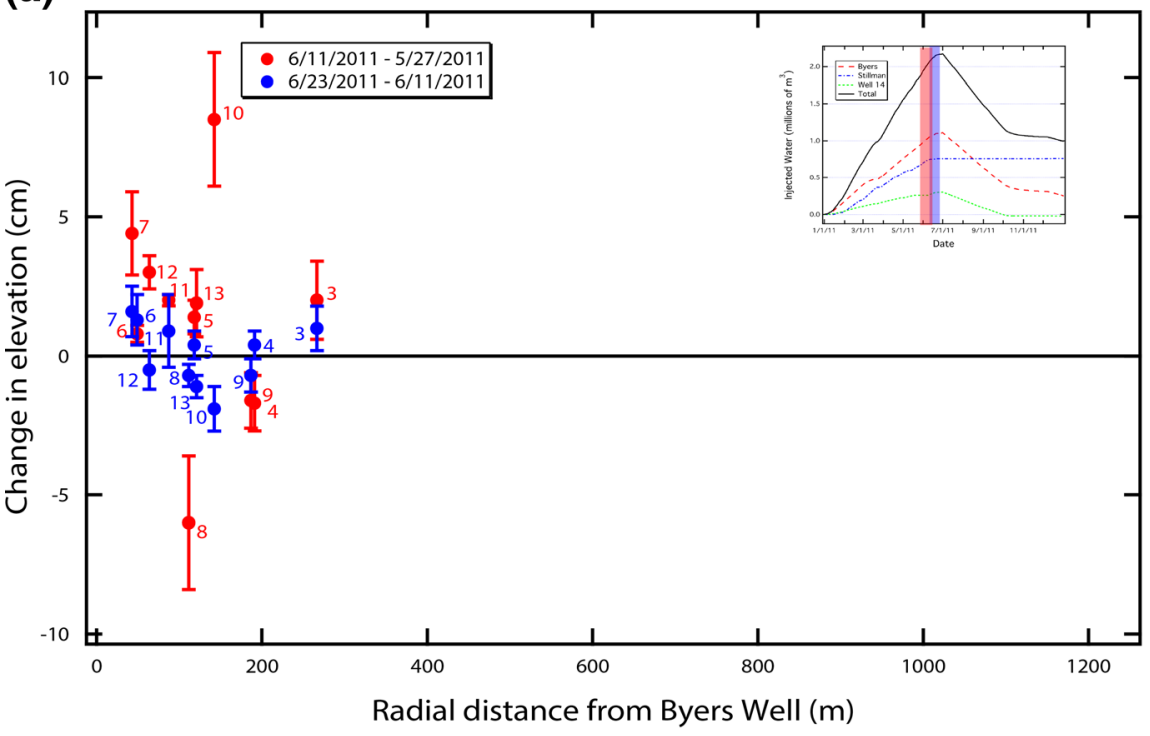

(b)

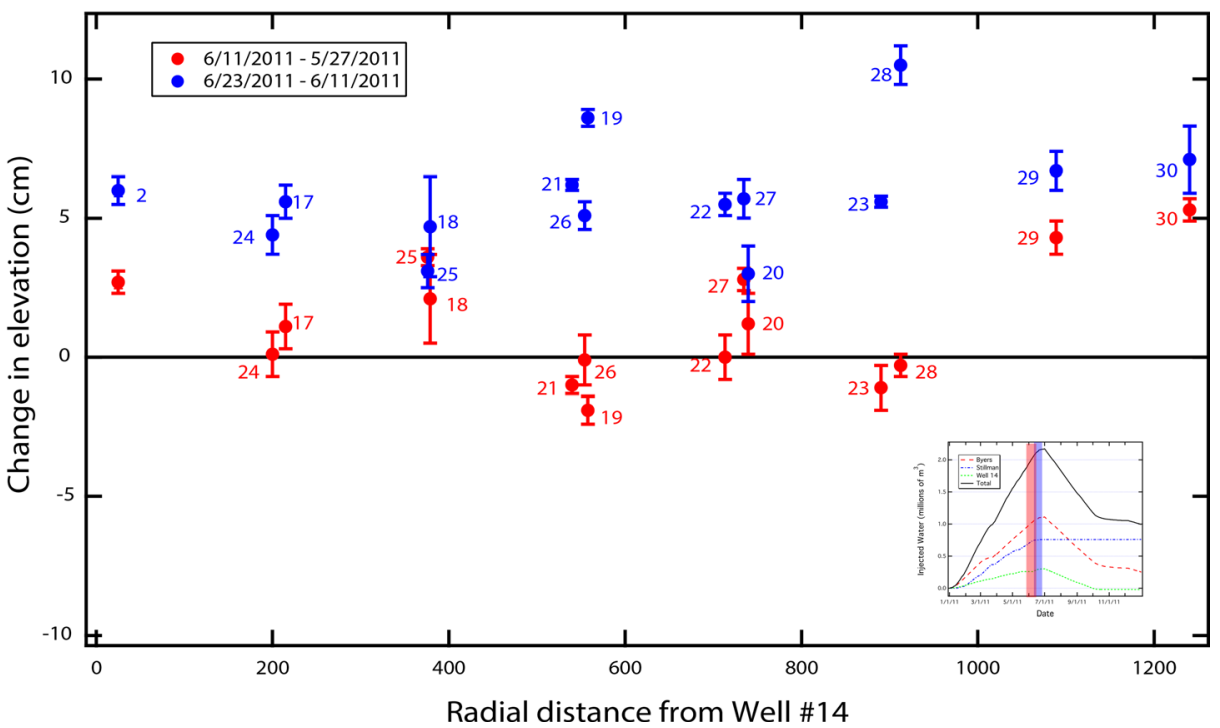

Fig. 3 Time-lapse GPS for Byers well and well 14 areas for two periods of time (red and blue points). The inset shows the corresponding stage of the water cycle for each period. a Time lapse GPS for Byers well during injection; b Time lapse GPS for well 14 during injection

changes from May 27 to June 23, 2011 do not show a strong correlation with radial distance except close to the well $(<150 \mathrm{~m})$ where deformation showed a negative slope (Fig. 3a). For stations surrounding well 14 (Fig. 3b), elevation changes from May 27 to June 23, 2011, as a function of radial distance and for distances less than $700 \mathrm{~m}$, suggested a poor positive correlation with an $r^{2}=0.59$ and a negative slope. For radial distances more than $700 \mathrm{~m}$ from 
well 14, a positive slope was observed and may have been the result of a process other than injection at well 14. Both the correlation and magnitude of the observed elevation changes from May 27 to June 11, 2011 are lower than for the June 11 to June 23, 2011 period and may suggest that the differences in geology and injection rates at this well have played a significant role.

\subsubsection{Large-Scale Deformations}

Observed elevation changes (Fig. 3a and 7b) were largest during the injection period from June 11 to June 23, 2011 at well 14 and between May 27 and June 6, 2011 for Byers well; a positive average deformation of $7.1 \pm 4.6 \mathrm{~cm}$ was shown for all stations, including the error from possible base station movement. After the injection period from June 23 to September 13, 2011 (not represented), observed elevation changes for all stations showed insignificant deformation $(-0.9 \pm 1.6 \mathrm{~cm})$.

\subsection{Gravity Data (Fig. 4)}

\subsubsection{June 5 to July 25, 2011}

Near Byers well, 7 of the 11 measured stations presented reduced gravity values $\Delta \mathrm{g}$ well outside the calculated error, all of which showed a positive gravity anomaly. The average $\Delta \mathrm{g}$ for stations above the error was $36 \pm 16 \mu$ Gal. Near well 14,9 of the 15 stations were outside the calculated error and again, they all showed a positive gravity anomaly averaging $49 \pm$ $24 \mu \mathrm{Gal}$.

\subsubsection{July 25 to September 25, 2011}

Near Byers well, 9 of the 11 stations presented $\Delta \mathrm{g}$ outside the calculated error, all but three (3, 4 and 5) of which showed a negative gravity anomaly. The average $\Delta \mathrm{g}$ for the stations outside the error was $-34 \pm 21 \mu \mathrm{Gal}$. In contrast, near well 14 , all of the stations presented $\Delta \mathrm{g}$ well outside the calculated error and all showed a negative gravity anomaly averaging $-175 \pm$ $22 \mu \mathrm{Gal}$.

\subsection{DInSAR Data}

A coherence threshold of 0.6 is assigned for the DInSAR/SBAS analysis and the corresponding time series displacement maps in order to account for surface temporal and spatial decorrelation which causes an interferometric phase error. These errors are quantitatively estimated with the calculation of the interferometric coherence. The temporal correlation (i.e., coherence below 0.6) was especially weak over crop fields around the Pendleton city where surface roughness, vegetation, and soil moisture vary frequently; but the main area of interest, the city itself, show a strong coherence. Figure 5 shows the DInSAR time series in the radar LOS direction at the points A, B, C respectively close to the wells Stillman, Byers and 14, and also point D located $8 \mathrm{~km}$ from the city. This time series were inverted using a Radarsat-2 interferograms dataset from July, 2011 to March, 2013. 
(a)

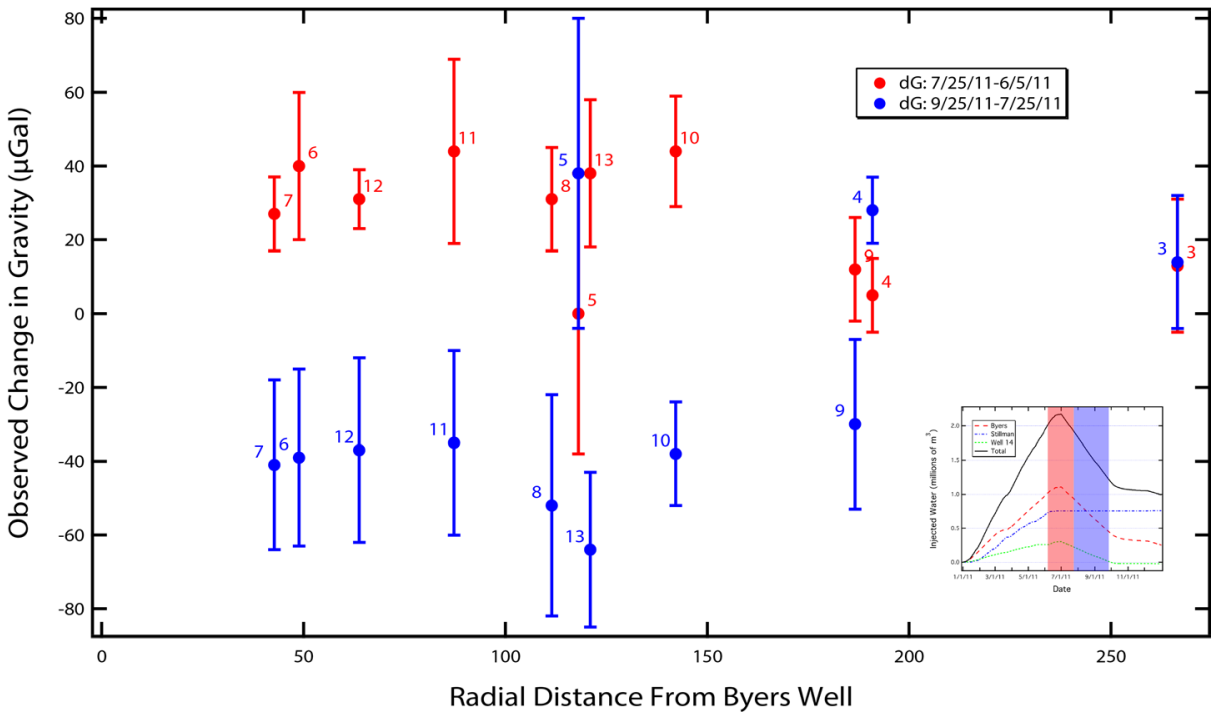

(b)

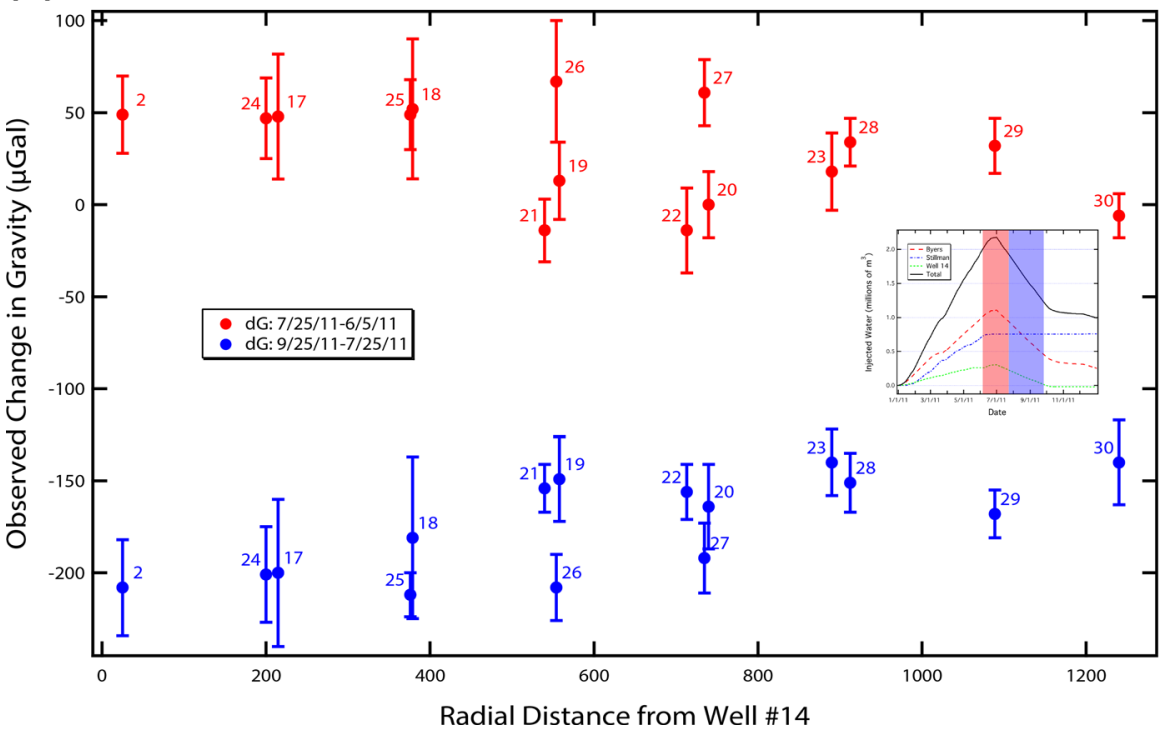

Fig. 4 Time-lapse changes in gravity for the Byers well and well 14 areas for two periods of time (red and blue points). The inset shows the corresponding stage of the water cycle for each period. a Time lapse gravity for Byers well; b Time lapse gravity for well 14

On the Radarsat-2 DInSAR/SBAS Time Series shown in Fig. 5, the pixels temporal evolution on reference points $\mathrm{A}$ and $\mathrm{B}$ shows a $\sim 14$ months periodic displacement with a 4 to $6 \mathrm{~mm}$ uplift from summer 2011 to spring 2012 and a $3 \mathrm{~mm}$ subsidence from spring 2012 to fall 2012. From fall 2012 to spring 2013 no major displacement is observed in those points. The periodic trend is observed on point $\mathrm{C}$ but with a much smaller amplitude variation of 

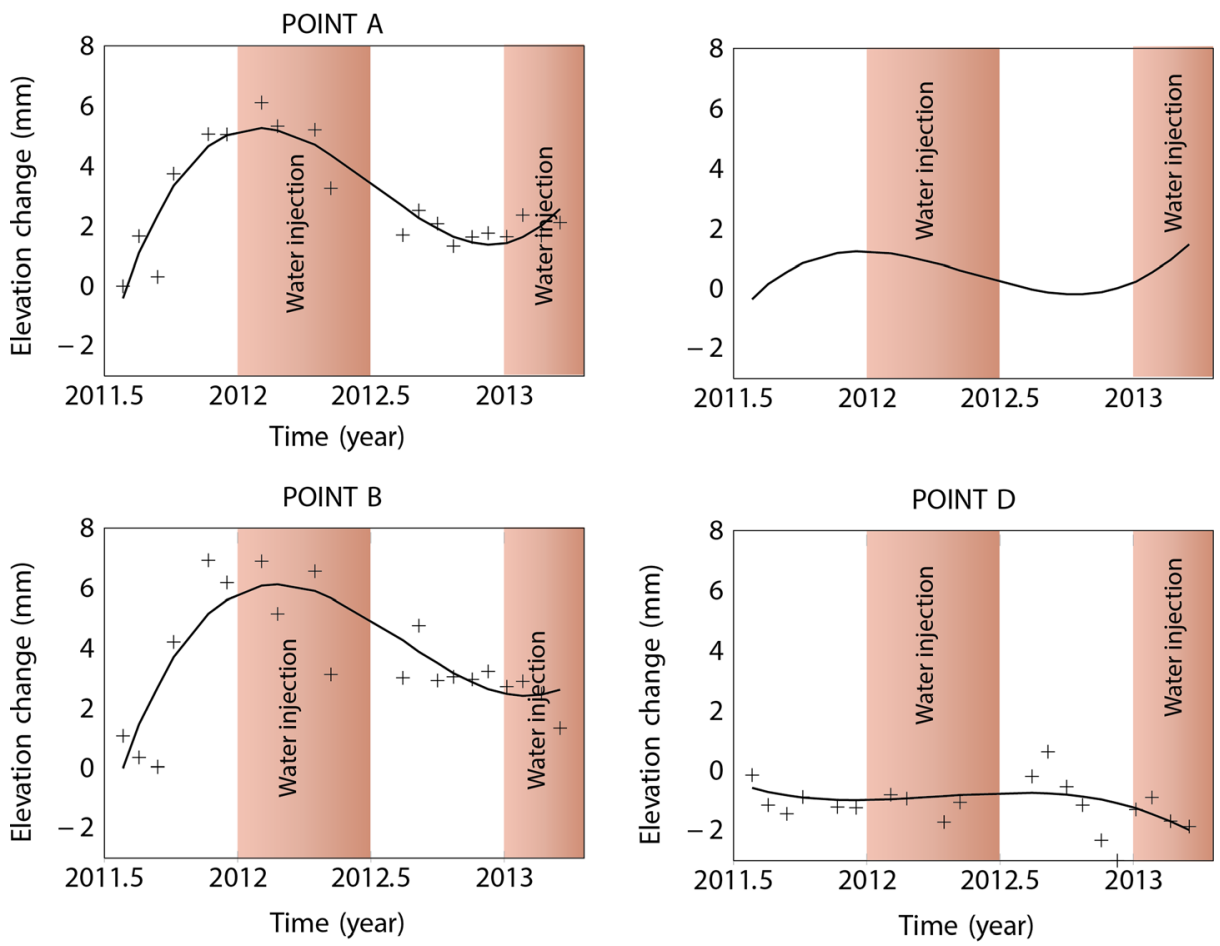

+ RADARSAT-2 SBAS

RADARSAT-2 SBAS fit

Fig. 5 DInSAR/SBAS elevation change LOS time series and fitting function over points $\mathbf{a}, \mathbf{b}, \mathbf{c}$ and $\mathbf{d}$ located on Fig. 2. Periods of water injection are shown

$\sim 2 \mathrm{~mm}$ from July, 2011 to March, 2013. At $8 \mathrm{~km}$ from the city, the time series for point D is stable and does not show evidence of displacements within our $1 \mathrm{~mm} / \mathrm{year}$ precision. The pixels temporal evolution nearby the wells provides a valuable measure of the ground response to the injection and recovery, but does not give insight into the extent of the deformation. Thus, using DInSAR displacement maps, deformation patterns can be localized and measured.

Displacement maps (available on request) show similar deformation amplitude to the pixel temporal evolution observed on points A and B, which are a $\sim 3 \mathrm{~mm}$ uplift from July, 2011 to February, 2012 and a 4-6 mm subsidence from February, 2012 to November, 2012.

\section{Discussion}

DInSAR/SBAS monitoring of the Pendleton area suggests the occurrence of sub-centimetric deformations in Pendleton city away from the three injection/recovery wells. The displacement analysis using the 2011-2013 Radarsat-2 scenes are used here for our displacements assessment baseline as it has the adequate temporal and spatial coverage that is not reproduced in the DGPS and gravity data acquisitions. Although not collected synchronously to the satellite data, DGPS and gravity could be compared to the measured DInSAR LOS measured displacements. 
Even though 2 years of observations are not enough to assess the full periodicity of ground deformations, our LOS displacements suggest that amplitudes of ground deformations in response to injections and recoveries are not evenly distributed along the Pendleton city. Point $\mathrm{A}$ and $\mathrm{B}$ show a $\sim 6 \mathrm{~mm}$ maximum displacement while point $\mathrm{C}$ shows less than $2 \mathrm{~mm}$ displacement over the same time period. Moreover the observed period of LOS displacements is relatively out-of-phase by a few months from the injection and recovery events. This could be due to the duration of the injection and recovery events, the volume of the injected water as well as complex groundwater flow occurring in the aquifer and that goes beyond the reach of this study. Finally we observe that after each injection and recovery cycle points A and B do not return to the same level they were in the beginning of the cycle suggesting that some of the deformations induced by the injection and recovery can have an accumulative effect on the ground elevation and correspond to water stored.

In contrast, DGPS field data showed a small positive but significant signal near both injection wells that fits closely with the timeline of injection - the June 25 survey was conducted near the end of injection period and the July survey was conducted shortly after extraction began. This appears to be at odds with the negative signals that are evident between July and September, but in fact matches the injection and extraction records. Byers well is approximately $1.3 \mathrm{~km}$ from Stillman well, which is also an injection point in the Pendleton ASR. Due to air entrainment, Stillman well has not been suitable for use as an extraction well, so the water near Byers well is not extracted nearly as quickly as it is injected. In contrast, Pendleton City records indicate that more water is extracted annually from well 14 than is injected. It has to be noted that no tectonic activity or any man made subsurface activity have been recorded in the area during the 2 years of observations.

Let's try now to interpret these deformations in terms in change of stress at depth. For a linear elastic material, a change in stress or pressure leads to a proportional change in strain or the volume of the material. Water pressure changes within a confined aquifer impart stress changes on both the fluid itself and the geologic formation. The total stress is due to the overlying rock/soil and water and is supported by both the fluid and the geologic material. The portion supported by the geologic material is called the effective stress (Terzaghi 1925). Stress changes can induce volumetric changes by compressing both the water and solid materials or by rearranging the granular porous matrix. If the changes in the total stress are assumed to be negligible, the effective stress is the negative of the change in fluid pressure. If this is the case, an increase in hydraulic head (that might occur during injection of water), would decrease the effective stress acting on the geologic formation. For stress acting only in the vertical direction, the effect would be to cause an increase in the elevation at the surface and this is what was observed in the DGPS signal. Various methods exist for analyzing subsidence due to groundwater withdrawal. Two commonly used approaches are based on conventional groundwater flow (Jacob 1940; Jacob 1950) and linear poroeleasticity (Biot 1941).

In our study, the ground surface deformation due to the injection and withdrawal of water was modeled using the STOMP simulator (White and Oostrom 2006) for modeling subsurface flow of water and RIEM, a rigid body-spring method (Kawai 1978; Fang et al. 1998) for modelling the deformation. The simulation was based on the following parameters and assumptions: the 3D model is $100,000 \mathrm{~m}$ wide by $100,000 \mathrm{~m}$ long and $335 \mathrm{~m}$ thick (Fig. 6); there is no flux boundary condition on the sides (tens of kilometers away from the wells); the majority of the model is impermeable basalt with interflow permeable zones in which water is injected and Byers well, Stillman well, and well 14 were represented using a vertical string of high permeability zone with area of $0.04 \mathrm{~m}^{2}$. The equivalent total screened interval was 


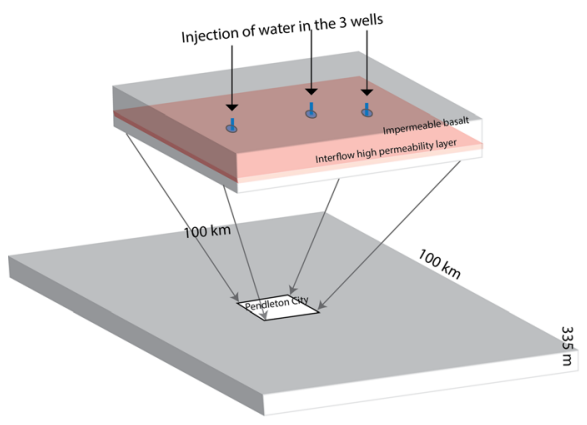

(b)

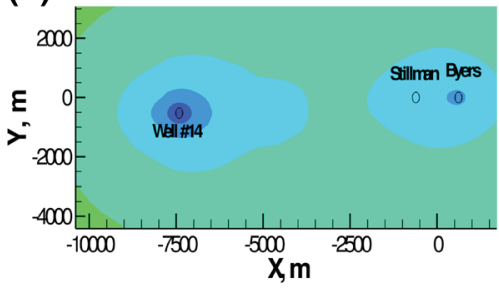

(a)

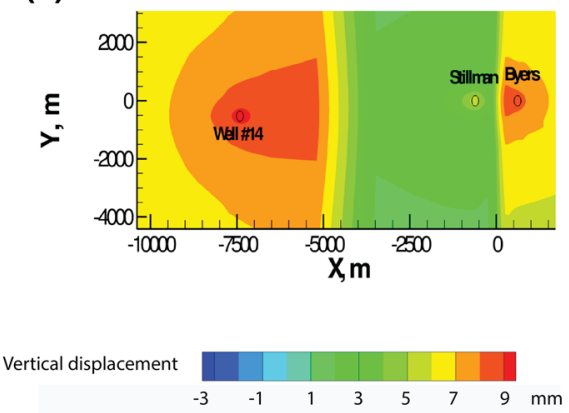

(c)

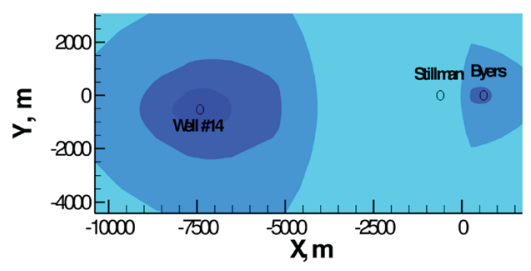

Fig. 6 Geometry of the mechanical model and modeled vertical displacement in a May, b Mid July, and c September 2011

assumed to be 30 (cumulative thickness of permeable layers). Three zones of hydraulic conductivity were estimated based on the water table and injection rate: $K=259 \mathrm{~m} /$ day for the zone surrounding Byers well, $K=61 \mathrm{~m} /$ day for well 14 , and $K=244 \mathrm{~m} /$ day for Stillman well. These values are consistent with the hydraulic conductivity values deduced from the ASR hydrologic feasibility study conducted in 2002 (CH2M-HILL 2002). The saturation function used the Brooks Corey formulation (Brooks and Corey 1966), and actual injection rates at the three wells were used. To test the validity of the modeling, the resulting water levels were satisfactory compared with field measurements at the three wells for 2011. During the injection period, the surface experienced uplift, highest near the well, lower farther away from the well. The GPS measurements (Fig. 3) indicated that deformation changes at well 14 are of the same order of magnitude as the ones observed at Byers well, but the change in water level in the wells and thus pressure are slightly different, suggesting the rock at well 14 has a lower Young's modulus. Similarly, for Stillman well the rock formation should be the stiffest because it experiences the largest pressure change. To explain the GPS measurements, the Young's modulus in the impermeable zones surrounding well 14, Stillman and Byers wells were assumed to be $1.7,7.5$, and $2.5 \mathrm{GPa}$, respectively. The Young's moduli in the permeable zones were chosen to be 30 times less than those of the impermeable zones. The corresponding results are presented in Fig. 6 which shows contours of the modeled deformation around the three wells on May 27, July 25, and September 13, 2011 corresponding to dates where GPS measurements were collected. The model qualitatively captures the behaviors observed in the field which is a larger displacement difference at well 14 and Byers well than at the places in between due to subsidence at those locations caused by pumping. However, the linear elastic model cannot explain the shift in time between the ASR events and the maximum of anomalies observed on DinSAR data (Fig. 5). The flow interiors consists of basalt that contains numerous 
cooling joints formed as the lava solidified. Studies (Lindberg 1989) found that these joints are 77 to $99 \%$ filled with secondary minerals, such as clay, zeolite, etc. Precipitation in June could put water in contact with joints in basalt, which can cause clay expansion. The rock can also undergo unrecoverable plastic deformations when a load level greater than any historical load is reached (Lubliner 1990). Clay expansion together with the irreversible plastic deformation in rock might explain the long wavelength out of phase effect observed on DInSAR data.

How do all the deformation observations compare with the gravity observations? We have observed that the variations with time close to the two injection wells are important and above the error bars in both elevation and gravity, especially between June 5 and July 25, 2011. Gravity and elevation variations are not anti-correlated, rather they appear to be correlated and thus gravity changes cannot be explained only by elevation changes (free air gravity anomaly). For well 14 (Fig. 4b), one should note the good correlation of the gravity anomalies observed for both periods of time. The effects of the nearby river, the associated water table, and their variations in level with time were computed using a 3D numerical modeling method (ENcom Model Vision ${ }^{\mathrm{TM}}$ ) and can be considered negligible. In another hand, injection of water in a confined aquifer is not accompanied by any gravity anomaly so we have to find another explanation and look at the effect of injection in the unsaturated zone. When an unconfined system is infiltrated by a mass of water at a single location, a "bubble" or "mound" of water forms within the host medium with maximum vertical thickness at the center of the infiltration location (Hantush 1967). However, in the case of Pendleton's basalt aquifer system the thickness of an injected "bubble" of water is limited to that of the porous interflow zone into which it is injected. Because of this, injected water is more correctly described as a disc of roughly constant thickness that extends away from the injection site. For a first order analysis, this disc could be treated as an infinite slab. The thickness $h$ of an infinite slab can be simply expressed as

$$
h=\frac{\Delta g}{2 \pi \mathrm{G} \Delta \rho}
$$

where $\Delta \mathrm{g}$ is the gravity anomaly, $\mathrm{G}$ the gravitational constant and $\Delta \rho$ the change in density. Interflow zone porosity has been estimated to be $15 \%$ (CH2M-HILL 2002). If void pore space is replaced with water $\left(\rho=1000 \mathrm{~kg} \cdot \mathrm{m}^{-3}\right)$, then $\Delta \rho=150 \mathrm{~kg} \cdot \mathrm{m}^{-3}$. Using these parameters and the observed Byers well $\Delta \mathrm{g}$ of $30-45 \mu \mathrm{Gal}, 5$ to $7 \mathrm{~m}$ of unsaturated interflow zone would explain the observed $\Delta \mathrm{g}$.

In the case of deeper interflow zones, the injection is not filling void space, but rather pushing native groundwater out of the way to accommodate injected water, resulting in no net difference in density, $\Delta \rho$. However, water levels in the wellbores increase during injection, which could in turn make "dry" interflow zones into injection targets. At Byers well, the $\Delta \mathrm{g}$ of $-40 \mu \mathrm{Gal}$ observed between July and September 2011 could easily be explained by the "drying out" of an interflow zone that was saturated during the injection cycle.

At well 14, the $\sim 50 \mu \mathrm{Gal} \Delta \mathrm{g}$ between June and July 2011 is also characteristic of a 5- to 8$\mathrm{m}$ "dry" interflow zone becoming saturated by injection. The $\Delta \mathrm{g}$ between July and September, however, suggests 24 to $32 \mathrm{~m}$ of saturated interflow zone becoming dry, which is unlikely to be explained by the ASR alone. Beginning approximately in May, the water level in well 14 began a gradual decline, despite the fact that water was being injected, a trend that was not 
observed at either the Byers or Stillman wells. One possible explanation for this decline is agricultural water use.

\section{Conclusion}

Injection of water at the three wells of the Pendleton ASR project in 2011 and its recovery at two of them are accompanied by significant gravity anomalies and surface deformations of the ground localized to the immediate surroundings of the injection wells as evidenced by GPS and gravity field measurements. GPS field surveys are essential to constrain the maximum amplitude and the wavelength of the deformation and thus give valuable insight into the mechanical properties of the reservoir and overburden. The gravity signal in this particular context gives additional insight into the repartition of water masses in the unconfined zones. Providing the number of scenes collected is sufficient, DInSAR could allow mapping the spatial extent of the deformation. A numerical simulation of the effect of the water injection and pumping based on hydrological data and mechanical properties of the lithological column gives results in good agreement with the observations and confirm the applicability of the approach that could be deployed with better confidence in similar geological contexts to look at the mechanical effects of fluid injections (water or gas).

Despite the positive and very encouraging results obtained with this first study, a good lesson learned is that a more careful protocol of field data acquisition should be designed. In particular, the survey dates need to be carefully defined based on the anticipated water cycle and one GPS permanent station should be deployed for at least 2 years covering two complete ASR cycles and if possible prior to any cycle in order to get good baseline data. Both GPS and gravity surveys should also extend over 2 years and comprise points outside the area concerned by the water injection in order to better define the background noise (seasonal variations in particular). If for financial or operational reasons, not all the field methods can be deployed, DGPS survey and permanent GPS station should be preferred to gravity which remain difficult to operate. Gravity should be limited to the case where knowing where the water goes is of primary importance compared to the ground deformations assessment. It should also be noted that the lack of SAR scenes with enough time and spatial resolution remains a substantial challenge to accurately detecting and monitoring ground deformation for ASR projects and $\mathrm{CO}_{2}$ storage sites. Future SAR missions with interferometric capability will hopefully fill this gap.

Acknowledgments We are grateful to the City of Pendleton which gave us access to all ASR data and monitoring wells; in particular to B. Patterson, K. King and T. Smith. We thank F. Spane from PNNL, and M. Lavalle, M. Neumann, and K. Wolfenbarger from the Jet Propulsion Laboratory for their helpful comments and discussions. We thank two anonymous reviewers and the associate editor for their useful comments. We also thank the Canadian Space Agency (CSA) for providing the radar scenes through a science program. This work was carried out within the Zero Emissions Research Technology Center (ZERT) funded by the U.S. Department of Energy (US DOE), under Award No. DE-FC26-04NT42262. However, any opinions, findings, conclusions, or recommendations expressed herein are those of the author(s) and do not necessarily reflect the views of the US DOE.

\section{Compliance with Ethical Standards}

Funding This work was carried out within the Zero Emissions Research Technology Center (ZERT) funded by the U.S. Department of Energy (US DOE), under Award No. DE-FC26-04NT42262. 
Conflict of Interest The authors declare that they have no conflict of interest.

Human and Animal Rights and Informed Consent This Research does not involve Human Participants and/ or Animals.

Open Access This article is distributed under the terms of the Creative Commons Attribution 4.0 International License (http://creativecommons.org/licenses/by/4.0/), which permits unrestricted use, distribution, and reproduction in any medium, provided you give appropriate credit to the original author(s) and the source, provide a link to the Creative Commons license, and indicate if changes were made.

\section{References}

Allis RG, Hunt TM (1986) Analysis of exploitation-induced gravity changes at Wairakei geothermal field. Geophysics 51:1647-1660

US Army Corps of Engineers (2007) Control and topographic surveying engineering manual vol 1110-1-1005. Washington, DC

Bell JW, Amelung F, Ferretti A, Bianchi M, Novali F (2008) Permanent scatterer InSAR reveals seasonal and long-term aquifer-system response to groundwater pumping and artificial recharge. Water Resour Res 44: W02407. doi:10.1029/2007WR006152

Berardino P, Fornaro G, Lanari R, Sansosti E (2002) A new algorithm for surface deformation monitoring based on small baseline differential SAR interferograms. IEEE Trans Geosci Remote Sens 40:2375-2383

Biegert E, Ferguson J, Li X (2008) 4D gravity monitoring - introduction. Geophysics 73:WA1-WA2

Biot MA (1941) General theory of three-dimensional consolidation. J Appl Phys 12:155-164

Brooks RH, Corey AT (1966) Properties of porous media affecting fluid flow J Irrig Drain Div ASCE 61-88

Burbey TJ (2001) Storage coefficient revisited: Is purely vertical strain a good assumption? Ground Water 39: 458-464. doi:10.1111/j.1745-6584.2001.tb02330.x

Burbey TJ, Warner SM, Blewitt G, Bell JW, Hill E (2006) Three-dimensional deformation and strain induced by municipal pumping, part 1: analysis of field data. J Hydrol 319:123-142. doi:10.1016/j.jhydrol.2005.06.028

CH2M-HILL (2002) Aquifer storage and recovery-hydrogeologic feasibility study for the City of Pendleton. CH2M-HILL, Portland

Chapman DS, Sahm E, Gettings P (2008) Monitoring aquifer recharge using repeated high-precision gravity measurements: a pilot study in South Weber. Utah Geophys 73:WA83-WA93

City of Pendleton (2009) ASR project: 6th annual report, pilot test, cycle 7

Fang Y, Zhuo J, Zhang Q (1998) Interface stress element method for discrete model with elements of arbitrary shape. Eng Mech 15:11, in Chinese

Fialko Y, Simons M, Agnew D (2001) The complete (3-D) surface displacement field in the epicentral area of the 1999 MW 7.1 Hector mine earthquake, California, from space geodetic observations. Geophys Res Lett 28: 3063-3066. doi:10.1029/2001g1013174

Gabriel AK, Goldstein RM, Zebker HA (1989) Mapping small elevation changes over large areas: differential radar interferometry. J Geophys Res 94:9183-9191. doi:10.1029/JB094iB07p09183

Galloway DL, Burbey TJ (2011) Review: regional land subsidence accompanying groundwater extraction. Hydrogeol J 19:1459-1486. doi:10.1007/s10040-011-0775-5

Gambolati G, Teatini P, Ferronato M (2006) Anthropogenic land subsidence. In: Encyclopedia of hydrological sciences. Wiley, New York. doi:10.1002/0470848944.hsa164b

Hanssen RF (2001) Radar interferometry: data interpretation and error analysis vol 2. vol Remote Sensing and Digital Image Processing. Springer Netherlands, Amsterdam. doi:10.1007/0-306-47633-9

Hantush MS (1967) Growth and decay of groundwater-mounds in response to uniform percolation. Water Resour Res 3:227-234. doi:10.1029/WR003i001p00227

Henning W (2010) National Geodetic Survey User Guidelines for Single Base Real Time GNSS Positioning. U.S.Department of Commerce, National Oceanic and Atmospheric Administration, National Geodetic Survey, Rockville, Maryland, USA

Jacob CE (1940) On the flow of water in an elastic artesian aquifer. EOS Trans Am Geophys Union 21:574-586

Jacob CE (1950) Flow of groundwater. In: Rouse H (ed) Engineering hydraulics. John Wiley, York, pp 321-386

Kawai T (1978) New discrete models and their application to seismic response analysis of structures. Nucl Eng Des 48:207-229 
Leirião S, He X, Christiansen L, Andersen OB, Bauer-Gottwein P (2009) Calculation of the temporal gravity variation from spatially variable water storage change in soils and aquifers. J Hydrol 365:302-309. doi:10. 1016/j.jhydrol.2008.11.040

Lindberg JW (1989) A numerical study of cooling joint width and secondary mineral infilling in four Grande Ronde Basalt flows of the central Columbia Plateau, Washington. In: Reidel SP, Hooper PR (eds.) Volcanism and tectonism in the Columbia River flood-basalt province. Geological Society of America Special Paper:6

Lubliner J (1990) Plasticity theory. Macmillan Publishing, New York

Madsen SN, Zebker HA (1998) Imaging radar interferometry. In: Principles and Applications of Imaging Radar, Manual of Remote Sensing. 3rd edn. Wiley, New York pp 359-380

McGrail BP, Spane FA, Sullivan EC, Bacon DH, Hund G (2011) The Wallula basalt sequestration pilot project. Energy Procedia 4:5653-5660. doi:10.1016/j.egypro.2011.02.557

Morris JP, Hao Y, Foxall W, McNab W (2011) A study of injection-induced mechanical deformation at the In Salah CO2 storage project. Int J Greenh Gas Control 5:270-280. doi:10.1016/j.ijggc.2010.10.004

Poland JF (1984) Guidebook to studies of land subsidence due to ground-water withdrawal. UNESCO, Paris

Reidel SP, Tolan TL, Hooper PR, Beeson MH, Fecht KR, Bentley RD, Anderson JL (1989) The Grande Ronde Basalt, Columbia River Basalt Group - Stratigraphic Descriptions and Correlations in Washington, Oregon, and Idaho. In: Reidel SP, Hooper PR (eds) Special Paper, vol 239. Geological Society of America, Boulder, Colorado

Reidel SP, Spane FA, Johnson VG (2002) natural gas storage in basalt aquifers of the Columbia Basin, Pacific Northwest USA: A Guide to Site Characterization. Richland, WA

Roman I (1946) An observational method to overcome zero drift error in field instruments. Geophysics 11:466490

Rosen PA, Hensley S, Joughin IR, Li FK, Madsen SN, Rodriguez E, Goldstein RM (2000) Synthetic aperture radar interferometry. Proc IEEE 88:333-382

Stewart G (1993) On the early history of the singular value decomposition SIAM. Review 35:551-566. doi:10. 1137/1035134

Terzaghi K (1925) Erdbaumechanik. Franz Deuticke, Vienna

Vasco DW et al. (2010) Satellite-based measurements of surface deformation reveal fluid flow associated with the geological storage of carbon dioxide. Geophys Res Lett 37 doi:10.1029/2009g1041544

White MD, Oostrom M (2006) STOMP subsurface transport over multiple phases, version 4.0, user's guide. Pacific Northwest National Laboratory, Richland, Washington, USA 